\title{
Biochemical changes associated with babesiosis infested cattle
}

\author{
Omnia. M. Abdel Hamid ${ }^{1}$, Mervat E.I Radwan² and Abdel Fatah Ali $^{3}$ \\ 1-Biochemistry department -faculty of veterinary medicine - Benha University \\ 2- Veterinary medicine department - veterinary hospital medicine - Benha University \\ 3 -Department of clinical pathology, veterinary Hospital Benha University
}

\begin{abstract}
:
Bovine babesiosis is a blood disease. Tick transported parasites leading to hemolysis of erythrocytes and produce anemia. In this study animals selected from endemic area of babesia Bigemina infection. The acute form of disease generally characterized by rapid growth and multiplication of parasite in blood which can examine and detected under microscope. Animals were divided into 4 groups : first group act as normal healthy control (20 buffalo), second group was infected group and divided into 3 sub group (50 each) first sub group was control infected group not treated, second infected group was treated by imidocarb + Vit $E$ and third sub group was treated by imidocarb as antibabesiosis.

Blood samples were collected once and divided into 2 sample one sample put on anticoagulant for measure erythrocyte antioxidants (G6PD, SOD, GPX, GR and L.MDA) the other blood sample used for separation of serum to estimate $\mathrm{NO}, \mathrm{Cu}$., $\mathrm{Fe}$,

$T A C$ and vitamin E. Results revealed significant decrease in antioxidants enzymes and increase in oxidants including (MDA\& NO) in infected group when compared with control. Vitamin E showing non significant decrease in infested animals while minerals showing different changes. All infected animals treated with imidocarb and vitamin E reveal improvement in all parameters as vitamin E ameliorate the oxidative effect of babesia by increase antioxidant effect.
\end{abstract}

Key words: Babesiosis, Oxidant, Antioxidant and Treatment

\section{Introduction}

Babesia is tick - transmitted intraerythrocytic protozoan parasites as many species are of considerable economic importance in live stock industry. Some species are zoonetic and affect human health. Invasion of animal erythrocytes by babesia species causes alteration in antioxidant potential of red blood cells (Annetta et al., 2003)

Intraerythroctic parasites invasion produce hemolytic effects by increase lipid peroxidation (Deger et al., 2001, Ginsburg et al., 1993) .as its demolish haematopioesis and cause anemia. This occurred anemia can cause decreased the levels of blood $\mathrm{Fe}, \mathrm{Ca}$ and $\mathrm{Cu}$. Moreover, infection of host causes host mediated pathology and erythrocyte lyses resulting in fever, hemoglobinuria, anemia and possibility of organ failure (Ahmed 2009). Recently, Babesia becomes the most wide spread parasite due to exposure of 400 millions cattle to infection though the world with consequent economic losses (Collett. 2000 and Kivaura et al., 2007). There is some evidence in support of oxidative stress and lipid peroxidation being a factor in the pathogenesis of anemia in babesiosis. Lipid peroxidation is a general mechanism and NO mediate host defense mechanism against many intracellular parasites (Brunet et al., 2001). Free radicals induce tissue damage and are implicated in several pathological conditions (Asri-Rejaet and Dalin. 2006). Overload of reaction oxygen species (ROS) including superoxide, hydrogen peroxides and hydroxyle radical that exceed the capacity of antioxidant system induce oxidative stress in the body, oxidative stress plays an important contributory role in a number of disease (Zaidinal.,et al., 2005) .Antioxidant vitamin as vitamin E protect cells from damage against oxygen free radical generated as result of parasitizes (Chuenkova et al., 1989 and Medzyaivicheysus et al., 1989) and has a protective role on the liver (Russel and Mc Dowed., 1989). The levels of trace elements minerals and vitamin are in normal range in healthy animal; however, their levels decrease significantly in illness and malnutrition. Therefore, this study was carried out to determined

1- Oxidative stress markers associated with babesia infection.

2- Using of vitamin $\mathrm{E}$ as antioxidant in treatment schedule.

\section{ANIMALS}

\section{Material And Methods}

Animals divided into 2 groups: group (1): consists of 20 buffalo free from babesioes act as control negative. Group (2) consists of 60 animals purchased from endemic area infected with babesia Bigemina in farms in 
Kaliobea governorates and Benha University education veterinary hospital. They confirm diagnosis by clinical signs and microscopic examination. Microscopic examination determined the degree of parasitaemia as recorded the percentage of infected red blood cells in each blood smear. These animals will divided into three subgroups (20 each) subgroup(1): without treatment as control positive, $\operatorname{subgroup}(2)$ : treated with imidocarb $(1 \mathrm{ml} \mathrm{I} / \mathrm{M}$ to each $100 \mathrm{~kg}$ body weight and Vitamin E( Tocosel-Forte injection $5 \mathrm{ml}$ dose $1 \mathrm{ml}$ per $50 \mathrm{~kg}$ I/M produced by Pharma Swede-Egypt Vit. E \&selenium) as antioxidant, subgroup (3): treated with imidocarb only.

\section{SAMPLING AND CHEMICAL ANALYSIS}

Blood samples were drawn from the jugular vein of each animal in two sterile test tubes after 2 weeks and they are divided into 2 parts. one part collected on EDTA and used for measuring of D6PD (Koronburg and Koecker1955), SOD (Nishikimi et al.,1972), GPX (Paglia and Valentine 1967), L.MDA (Esterbauer et al.,1982) and GR (Goldberg and Spooner 1983) and the second part was left for serum separation. It's centrifuged at $3000 \mathrm{rpm}$ for $15 \mathrm{~min}$. Then serum aspirated and used for estimation of $\mathrm{Cu}$ (Asi 1983), Fe (Anonim 1980), NO (Montaogmery and Dymock 1961), TAC (Beutler et al., (1963), and vitamin E (Martinek 1964).

\section{STATISTICAL ANALYSIS}

The results were Statistical analyzed by a analysis of the variance (ANOVA) followed by the Duncan test for multiple comparisons using computer SPSS 13.0 software 2009, Duncan's Multiple Range Test

\section{Results}

\section{Fig 1: Clinical signs and microscopic examination of calves infected with babesia}

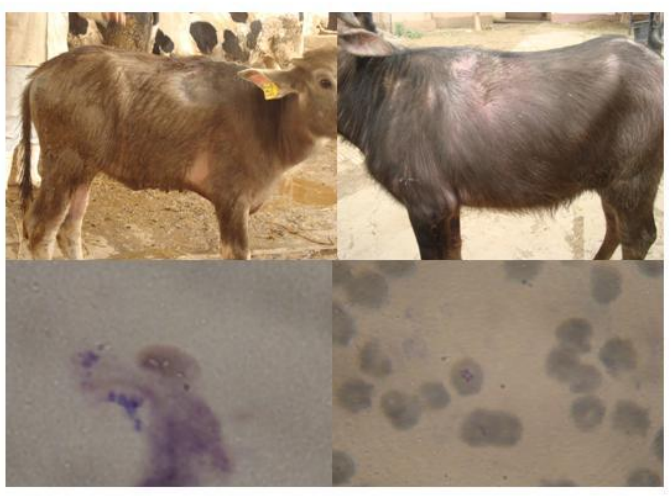

Fig (1): Showed emaciated animals with external parasites and blood stain film with geimsa stain showed erythrocytes infected with Babesia and binary fission four cells in RBCs characteristic shape for Babesia differentiated it from other protozoan as Malaria infected RBCs.

Table (1) Effect of babesia Bigemina infection in buffalo-calves ages 1-3years on some antioxidants /oxidants markers.

\begin{tabular}{|l|l|l||l|l|}
\hline \multirow{2}{*}{$\begin{array}{l}\text { Groups } \\
\text { Antioxidants } \\
\text { And oxidants }\end{array}$} & \multicolumn{2}{c|}{ Control Groups } & \multicolumn{2}{c|}{ Treated Groups } \\
\cline { 2 - 5 } & Healthy & Infected & $\begin{array}{l}\text { Imidocarb } \\
\text { and Vit.E }\end{array}$ & Imidocarb \\
\hline GPX & $10.4 \pm 0.4^{\mathrm{a}}$ & $7.08 \pm 0.89^{\mathrm{b}}$ & $8.85 \pm 0.3^{\mathrm{a}}$ & $8.08 \pm 0.66^{\mathrm{ac}}$ \\
\hline GR & $2.57 \pm 0.24^{\mathrm{a}}$ & $0.56 \pm 0.1^{\mathrm{b}}$ & $2.13 \pm 0.03^{\mathrm{a}}$ & $2.12 \pm 0.13^{\mathrm{ac}}$ \\
\hline
\end{tabular}


Biochemical changes associated with babesiosis infested cattle

\begin{tabular}{|l|l|l|l||l||}
\hline & & & & \\
\hline SOD & $13.13 \pm 0.75^{\mathrm{a}}$ & $7.78 \pm 0.11^{\mathrm{b}}$ & $12.0 \pm 0.65^{\mathrm{a}}$ & $10.7 \pm 0.39^{\mathrm{ab}}$ \\
\hline \hline G6PD & $119.5 \pm 0.99^{\mathrm{a}}$ & $82.0 \pm 8.25^{\mathrm{b}}$ & $101.3 \pm 3.4^{\mathrm{a}}$ & $87.68 \pm 5.74^{\mathrm{ac}}$ \\
\hline TAC & $6.23 \pm 0.29^{\mathrm{ac}}$ & $4.2 \pm 1.02^{\mathrm{a}}$ & $6.67 \pm 1.3^{\mathrm{b}}$ & $8.9 \pm 0.45^{\mathrm{a}}$ \\
\hline MDA & $0.88 \pm 0.07^{\mathrm{b}}$ & $2.19 \pm 0.28^{\mathrm{a}}$ & $1.11 \pm 0.64^{\mathrm{b}}$ & $1.16 \pm 0.029^{\mathrm{ab}}$ \\
\hline \hline NO & $62.0 \pm 2.52^{\mathrm{c}}$ & $100.7 \pm 1.45^{\mathrm{a}}$ & $79.0 \pm 2.1^{\mathrm{c}}$ & $91.2 \pm 1.76^{\mathrm{ab}}$ \\
\hline \hline CU & $99.80 \pm 4.9^{\mathrm{a}}$ & $80.43 \pm 4.52^{\mathrm{b}}$ & $95.77 \pm 4.52^{\mathrm{a}}$ & $91.20 \pm 1.76^{\mathrm{ab}}$ \\
\hline \hline Fe & $126.1 \pm 3.4^{\mathrm{bc}}$ & $165.9 \pm 16.6^{\mathrm{a}}$ & $133.5 \pm 1.4^{\mathrm{b}}$ & $154.5 \pm 3.22^{\mathrm{ab}}$ \\
\hline \hline Vit E & $0.46 \pm 0.05^{\mathrm{a}}$ & $0.22 \pm 0.33^{\mathrm{ab}}$ & $0.52 \pm 0.15^{\mathrm{a}}$ & $0.6 \pm 0.13^{\mathrm{a}}$ \\
\hline
\end{tabular}

Meanvalue \pm standard error.

Superscript with different letters showed significant difference while same letters showing non significant

Table 1: Revealed significant decrease in antioxidants including GPX, GR, SOD, G6PD and TAC in infected animals when compared to healthy control. Treatment with imidocarb as antibabesiosis or combination of imidocarb and vitamin E resulted in significant increase in these parameters. Moreover, oxidants as MDA and NO showing significant increase in infected cattle when compared to healthy control and by treatment revealed a significant decrease. Iron showing a significant decrease in infected group while treatment with imidocarb or imidocarb with vit $\mathrm{E}$ resulted in non significant increase when compared to infected group. $\mathrm{Cu}$ revealed significant decrease in infected group which indicated a significant increase after treatment. Vitamin E showed non significant decrease in infected group when compared to control. Treatment with imidocarb or imidocarb with vitamin $\mathrm{E}$ resulted in non significant increase in vitamin $\mathrm{E}$ level.

\section{Discussion}

Our results noted that parasitimic animals showed decrease in antioxidants (G6PD,GR ,SOD, GPX and TAC ) and trace element $(\mathrm{Cu}$ and $\mathrm{Fe})$ when compare with healthy animals and treated groups . This results came in agreement with Esmaeilnejad et al., (2012) who recorded a decrease in activity of SOD, GSH-PX, CAT and TAC in sheep infected with babesia whereas the MDA concentration was significantly increased. this may be due to that, babesiosis have oxidant antioxidant effect on buffaloes by increase lipid peroxide MDA and NO and decrease antioxidant enzymes (GSH-PX, SOD , GR) and change trace element antioxidant as Cu and Fe( EL.Moghazy, 2011). In addition to Azimzadeh et al., (2013) who recoded reduced activity of CAT, GSHPX and TAC) in sheep infected with babesia. Moreover, Osama and Gaada (2013) recorded that, calves infected with babesia resulted in significant increase in oxidant markers (MDA\&NO) and significant decrease in antioxidant parameters as SOD, GSH-R, Catalase, Ascorbic acid and TAC. The antioxidant system consists of antioxidants which act by scavenging the radicals directly and sustaining the activity of antioxidant enzymes by inhibiting the activities of oxidizing enzymes in intra erythrocytic parasites of theleria annulata and babesia bovis (Ali et al., 2013). Decrease blood level of GR was agreed with Muller et al., (1993) and Bicek et al., (2005) who reported that, GR plays a key role in cellular defense against oxidative stress by preventing accumulation of GSSG and thus maintaining the redox state. Moreover, it's known that, GSH and GPX represent a major pathway in the cell for metabolizing hydrogen peroxides and lipid peroxides so that the depletion of their level\Activity can lead to accumulation of peroxides increasing them to toxic levels (Genc et al., 1998). Nazifi et al., (2011) reported that, infected animals with theileriosis showed significant decrease in activities of antioxidant enzymes as SOD, GPX and serum concentration of $\mathrm{Cu}$ were evident in the infected animals in contrast, significantly increase level of MDA.

Manifestation of oxidative stress occurs due to either inadequate availability of antioxidant enzymes or uncontrolled production of free radicals-induced tissue damage and has been implicated in many pathological conditions. Babesia parasite, likes theleria and malaria parasites, invade erythrocytes of infected animals resulting in destruction of parasitized erythrocytes (OTSUKa et al., 2002). The liver plays a central role in babesiosis, It is the site where the pre-erythrocytic stages of babesia parasites asexually multiply and where host immature mechanisms develop to fight these pre-erythrocytic stages (Cohen et al., 1982). Current study showed a significant increase in oxidants including blood MDA and serum NO in infected animals when compared with control this may be attributed to that hemoparasitic diseases stimulates the production of 
various pro-inflammatory cytokines from mononuclear cells in animals and human beings these mediators activate the mononuclear, phagocytic cells to release oxygen and reactive nitrogen intermediates (Brown 1998, Brunet et al., 2001) and (Woldehiwet et al., 2010). Furthermore, babesia infection has a significant influence on augmented NO production and erythrocytic LPO and excess free radicals that leads to oxidative stress. Therefore it could be hypothesized that severity of Babesiosis is related to oxidative stress and loss of body's antioxidant reserve. This result came agree with Asri Raaei et al., (2006), Saleh et al., (2010) who recorded that, augmented erythrocytic LPO and decrease SOD activity have been reported in hemoparasitic infection like Babesia bigemina and Theileria annulated infection respectively, (Ergonul et al.,1992, Park,J. and Rikihisa 1992, Waytt et al.,1996) and (Court and Lee 2001) recorded that, plasma NO level elevated with oxidative burst and ROS production by bovine moncytes' and neutrophils during peak of parasitmia. MDA derived from LPO is an important indicator to decide the degree of oxidative damage of cell membrane and it increase when compare with healthy and treated groups and this agree with Sato et al., (1998), Bolchoz et al., (2002) who explained that, MDA reacts with cellular membrane elements and results to increase cellular permeability and enzyme activities. Furthermore, the membrane of erythrocytes is rich in polyunsaturated fatty acids and more vulnerable to peroxidative damage and come in same direction with Tsukahara et al., (2007). Loads of ROS included Nitric oxide and MDA over burden antioxidant systems induce oxidative stress in the body where major cellular targets of ROS are membrane lipids and Proteins. (Sedar et al.,2007) reported that, High MDA concentration in calves and cows infected with babesiosis (Cimer et al.,2008) reported that, erythrocytes particularly susceptible to an oxidative damage as a result of high polyunsaturated fatty acids content in their membrane and high concentration of oxygen and hemoglobin, hemoglobin is a potentially powerful promoter of oxidative processes .Babesia infection associated with free radical formation by changes antioxidant stress that is very dangerous to erythrocytes (Celi et al.,2010) Animals in our study treated with imidocarb as antibabesial drugs and antioxidant drugs as Vitamin E showed no significant difference between this group and healthy group after two weeks from administration of treatment. This result came agreement with Kamil et al.,2005), Ali et al.,(2013) who speculated that, antioxidant agent recommendation ,such as vitamin $\mathrm{C}$ and vitamin $\mathrm{E}$ may alleviate oxidative damage ,this vitamins are free-radical scavengers and could have a protective effect against oxidative damage and might be better in clinical improvement (animals appeared healthy, good clinical signs, approach from normal) and confirmed this good prognosis by evaluation (P6PD,GR-ase,SOD ). Nadia et al., (2003) observed that, treatment with $\alpha$-Tochopherol increase GSH and glutathione in reduce form has antioxidant properties to inhibits free radical formation and functions more generally as a redox buffer. Yukio et al., (2003) demonstrated that, pathogenesis of anemia associated with Babesia infection is partially derived from oxidation of the membrane of RBCs so injection of vitamin E may reduce oxidation procedures by increase antioxidants in RBCs. Henri et al., (2006) concluded that, imidocarb radical cure the infection only . But vitamins as $\mathrm{E}, \mathrm{C}$ and $\mathrm{A}$ protect the cells from damage against free radical oxygen generated as a result of parasites and have also protective role in the liver, the effect vitamin $\mathrm{E}$ as antioxidant appear in high concentrated $\mathrm{O} 2$ as in RBCs may play an important role in keeping stability of erythrocytes (Tocopherols have antioxidant activity as they react with molecular oxygen and free radicals thus prevent autoxidation of polyunsaturated fatty acids in tissues (cellular and sub cellular )

In this research serum iron revealed a significant decrease in infected animals when compared with control and by treatment serum iron level return to normal. This agreed with Lotfallah et al., (2012) who reported an significant decrease in iron concentration in cattle infected with babesia this may be explained that, oxidative damage to hemoglobin cause changes in its structure and function resulting in denaturation and precipitation of hemoglobin and methemoglobin formation inside erythrocyts. It's markedly increased in the onset of anemia in babesia infection. (Saleh 2009)

Vitamin E revealed a non significant decrease in infected animals when compared to control group and by treatment has non significant increase when compared with infected group . These results are in accordance with Commins et al., (1988) who reported that, antioxidative vitamin E decrease with babesia infection and cumulative change of these effect would be increase erythrocyte rigidity. Moreover, Azimzadeh et al.,(2013) reported a decrease in the level of vitamin E activity in sheep infected with babesia.

Taking together, the remarkable decrease in the level of antioxidant enzymes activities (G6PD,GR-ase,SOD) and the significant rise in the lipid peroxidation (MDA and NO), imply that, the babesia bigemina can interfere with the protective antioxidant mechanism of RBCs against oxidative injuries and the antioxidant vitamins were not able to prevent oxidative damage to RBCs membrane .So We advise with administration of vitamin .E and selenium as antioxidant which act as scavenger for free radicals to improve antioxidant mechanisms by increasing the activity of antioxidant enzymes and restoring to normal level 
Aknolgment

To all member stuff of education veterinary hospital Benha University wherever the experiment were performed.

\section{Reference}

[1]. Ahmed WM, Habeeb SM, El Moghazy FM and Emtenan MH (2009): Observation on pediculosis in buffalo-cows with emphasis on its impact on ovarian activity and control by herbal remedies. World APPL. Sci. J, 6: 1128-1138

[2]. Ali Hassanpour, Yousef Chader Sabegh and Ali Sadeghi- nasab.Assessment of serum aaaaantioxidant enzymes activity in cattle suffering from Theileriosis.European Journal of Expermintal Biology 2013, 3(1) : 493-496.

[3]. Annetta Zintl, Grace Mulcahy, Helen E. Skerret, Stuart M.Taylor and Jeremy S. Gray (2003): Babesia divergens, a bovine blood parasite of Veterinary and Zoonotic $\quad$ importance. Clinical. Microbiology Reviews, Oct, p. 622-636.

[4]. Anonym (1980): The quantitative colorometrik determination of iron and total iron-binding in serum. Sigma Technical ulletin. No565 Saint Louis. 63178 USA.

[5]. ASI t (1989): Elazig ve yoresinde koyum ve sigirlarda normal ve saghkla durumlarda kan sertumlarinda baker. Kalsiyum. Magnezyum ve anorganik fosfat degerleri uzerinde arastirmalar. Doga Bilim. Derg.D. 1.7.3:219-231

[6]. Asri Raaei,S and Dalir- Naghadeh B . Evaluation of antioxidant status and oxidative stress in cattle naturally infected with Theileria annulata .Vetrinary parasitology2006 . 142, 176-186

[7]. Beutler E, Duron O and Kelly BM (1963): Improved method for the determination of blood glutathione. J.Lab Clin. Med. 61 5:882-888.

[8]. $\quad$ Bicek K and Deger S (2001): van ve yoresi koyunlarinda babesiosisin ELISA ile teshisi. Y.Y.Ü. Sag. Bil. Derg, 7.1-2: 27-31.

[9]. Bolchoz LI,MorrowJD,JollowDJ,and McMillan DC, (2002) Primaquine -iduced hemolytic anemia ,effectof 6-methoxy -8hydroxylaminoquinoline on rat erythrocyte sulfhydrylstatus .membrane lipids, cytoskeletal, proteins and morphology . The journal Pharmacology and Expermintal Therapeutics (303):141-148.

[10]. Brown WC, Shkap V, Zhu D,Meguire TC., Tuo W, Meelwain TF,and Palmir GH, (1998) CD4+ T-Lymphocyte and immunoglobin G2Responses in calves immunized with anaplasma marginale outer membranes and protected against homologues challenge .Infection and Immunity ( 66):5406-5413

[11]. Brunet LR, (2001) Nitric oxide in parasitic infections international immunopharmacology .1:1457-1467 .Celi, P.,( 2010), Biomarkers of oxidative stress in ruminant medicine. , Immunopharmacol Immunotoxicol. Sep 18.

[12]. Chuenkova MV, Suckhareava NN, Sergacheva YY, Sokhaenkova TL, Soprunov FF and Grinberd LG (1989): The effect of vitamin Eon the lipid composition in mouse erythrocytes and in plasmodium berghei. Protozool. Abst. 013-01808.

[13]. Cimer MY, (2008)Free radical metabolism in human erythrocytes. Chin. Chim. Acta (390): 1-11

[14]. Cohen S, Lambert PH, Cohen S,Warren,(EDs) (1982) Immunology of parasitic infection ,Second Black Well scientific publication Oxford,pp.422-474

[15]. Collet MG (2000): Survey of canine babesiosis in South Africa. J.S. Afr. Vet. Assoc., 71: 180-186.

[16]. Commins M A., Goodger BV., Waltisbuh DJ. and Wright IG (1988): Babesia bovis: studies of parameters influencing microvascular stasis of infected erythrocytes. Research in Veterinary Science 44(2): 226-228.

[17]. Court RA, Jackson LA, and Lee RP , (2001) Elevated anti-par asite activity in prepheral blood monocytes and neutrophils of cattle infected with babesia bovis .International Journal of Parasitology 19:29-37.

[18]. Derger Y, Dede S, Kahraman T, Deger. S, Ormanci N and Bicek K (2001): Babesiosisli koyunlarda lipid peroksidasyonu, nitric oksit oksidasyon ÜrÜnleri ve antioksidan durumunun saptanmasi. Türkiye Parazitol Derg. 25, 1:25-27

[19]. EL.Moghazy FM , (2011) Effect of parasitic infection on oxidant/Antioxidant status in Buffaloes Middle-East Jornal Scientific. Research 7(4): 585-593 ISSN 1990-9233

[20]. Ergonul S, and Askar TK, (2009) The investigation of heat shock protein (HSP27), malondialdhyde (MDA),nitric oxide (NO) and interlukin (IL-6.IL-10) levels in cattle with anaplasmosis Kafkas University Vetrinary Fakultesi Dergisi .15:575-579

[21]. Esterbauer. H, Cheeseman. KH, Danzani. MU, Poli. G and Slater. TF (1982): Seperation and characterization of the aldhyde products of $\mathrm{ADP} / \mathrm{Fe}+{ }^{2} \mathrm{C}$ stimulated lipid peroxidation in rat liver microsomes. Biochem. J; 208:129-140.

[22]. Genc S,Gurdol F, Oner-Iyidogan Y,and Onaran I, (1998), The effect of melatonin administration on ethanol iduced lipid peroxidation in rats Pharmacological Research 37:37-40

[23]. Ginsburg H and Atamina H (1994): The redox status of malaria infected erythrocytes: an overview with an emphasis on unresolved problems. Parasite 18:5-13.

[24]. Goldberg. DM and Spooner. RJ (1983): UV method for determination of glutathione reductase activity. Method of enzymatic analysis (Bergmeyen, H.V.Ed.) $3^{\text {rd }}$ edn 3:258-265.

[25]. Henri J,Vital and Gorenflot A, (2006 ) chmotherapy against veterinary parasitology 138:147-160.

[26]. Kamil BicEK, Yeter DEGER \& Serdar DEGER Some biochemical and hematological parameters of sheep infected with babesia species YYU Vet Derg2005, 16(1) 33-35

[27]. Kaveh Azimz Adeh, Keyvan Nouri, Himan Farooghi, Sohrab Rasouli and Negar Zamani (2013): Plasma malonaldhyde, thyroid A and somr blood profile in ovine babesiosis. Kafkas. Univ. Vetfak Derg. 19(3): 489-493.

[28]. Kivaria FM, Rubeta MR, Mkonyi PA and Malamsha PC (2007): Epidemiological aspects and economic impact of bovine babesiosis (East cost fever) and its content preliminary assessment with special reference to kibahia district tanzania. Vet. J. 173 384-390.

[29]. Koracevic D and Koracevic G (2001): Clin. Pathol. 54: 356-361

[30]. Martinek R(1964): Method for determination of vitamin E (total tocopherol) in serum. Clin. Chem. 10.12:1078-1086.

[31]. Medzyavichysus AK, Bebravichyus VY, Bebravicius V, Drebickiene G and Medzevicius A(1989): Effect of vitamin A and C on immunity to trichuriasis in piglets under industrial farming condition. Acta. Parasitol Lit 23:115-129.

[32]. Montgomery. H.A.C and Dymock. J.F.(1961): Colorimetric determination of nitrite. Analyst 86:414.

[33]. Muller JG, Bucheler US, Kayser K, Schrimer,R.H.,Werner,D. and Krauth.siegel, RGlutathione(1993) reductase in human and murine lung tumors, high levels of m RNA \& enzymatic activity.cell. Mol.Biol. .39:389-396.

[34]. Nadia Z,Shaban,Madiha H , Helmy,Mohmed ARE, Kersh,Bothaina F, Mohmed (2003 ) Effect of Bacillus Thuringiensis toxin on hepatic lipid peroxidation and free radical scavengers in rats given alpha-tocopherol or a catylsalicy, comparative Biochemistry and Physiology partC135:405-414

[35]. Nazifi S, Razvi SM, Kianiamin P, Rakhshandehroo E , (2011) Evaluation of erythrocyte antioxidant mechanisms: antioxidan enzyme Lipid perixidations and serum trace element associated with progressive anemia in ovine maligant theileriosis. Parasitol Res. Aug: $\log (2): 275-281$ 
[36]. Nishikimi. M, Rao. N.A and Yogi. K(1972): Colorimetric determination of superoxide dismutase. Biochem. Bioph. Common. 46:849-854.

[37]. Osama F.A and Gaada H.I.M (2013): Evaluation of antioxidant response mechanism in fattening cattle calves suffering from babesiosis in New- Valley Governorate. Egypt. J. Vet. Adv, 31 (8): 232-237.

[38]. OTSUKa Y, Amasaki M, Yamato O, Maede Y(2002)The effect of macrophages on the erythrocytes oxidative damage and pathogenesis of anemia in Babesia gibson- infected dogs with low parasitemia J.Vet.Me.d. Sci. 64:221-223.

[39]. Paglia. D.E and Valentine. W.N (1967): UV method for determination of glutathione peroxidase activity. J.Lab. Clin. Med.70:158-169.

[40]. Park J,and Rikihisa Y, Arginine L, (1992) dependant Killing of intracellular Ehrlichiaristicii by macrophages treated with gamma interferon.Infection and Immunity, 60:3504-3508 .

[41]. Saleh MA, Mahran OM, and Bassem Al-Salahy (2010)Circulating oxidative stress status in dromedary camels infested with sarcoptic mange. Vet. Res. Common., 35:

[42]. Samad Lotfallah Zadeh, Masoud Rahmani, Mehrdad Mohri and Omid Madadgar (2012): Changes in serum iron concentration and hepatic enzyme activities in cattle infected with Theileria annulata and babesia bigmina.comparative Clinical Pathology 21(5):829-832.

[43]. Sato y,Kanazawa S, Sato K,and Suzuki Y, (1998)Mechanism of freeradical induced hemolysis of human erythrocytes:II.Hemolysis by lipid soluble radical initiator, Biological and Pharmaceutical Bulletin ,21:250-256.

[44]. Sedar D, Yeter B, Kamile and Ozdaland NAG, (2009) Status of Lipid Peroxidation, Antioxidants and Oxidation products of Nitric oxide in Equine Babesiosis: Status of Antioxidant and Oxidant in Equine Babesiosis. J. Equi. Vet. Sci. 29:743-774

[45]. Tsukahara H, (2007) Biomarkers for oxidative stress: clinical application in pediatric medicine., Curr. Med. Chem., 14:339-51.

[46]. Waytt CR,Davis WC, Knowles DP,Goff WL,Palmer GH, and McGuire TC, (1996)Effect on intraerythrocytic Anaplasma marginale of soluble factors from infected calf blood mononuclear cells, Infection and immunity ,64:4846-4849

[47]. Woldehiwet Z, (2010)The natural history of Anaplasma phagocytophilum,Veterinary parasitology ,167:108-112

[48]. Yukio ya gI, Prasobporn ThoNgNo oN, Hiroki Shiono and Yukio Chik AyAMA, (2002) Increase in oxidized proteins in Theileria-infected erythrocytes membrane.J.Vet.Med.Sci.64(7):623-625.

[49]. Zaidi SM., AL-Qirim. TM and Bani N (2005): Effect of antioxidant vitamins on glutathione depletion and lipid peroxidation induced by restrained stress in the rat liver. Drug R.D.pp: 157-165. 